\title{
Compared Analysis of LncRNA Expression Profiling in pdk1 Gene Knockout Mice at Two Time Points
}

\author{
Hailang Liu ${ }^{a, d}$ Guixian Songa,d Lijuan Zhou Xiaoshan Hu ${ }^{\mathrm{b}}$ Ming Liu ${ }^{\mathrm{a}}$ \\ Junwei Niec Shuangshuang Luc Xiangqi Wua Yunshan Cao ${ }^{\mathrm{a}}$ Lichan Tao \\ Ling Chen ${ }^{\mathrm{b}}$ Lingmei Qian ${ }^{\mathrm{a}}$
}

aDepartment of Cardiology, The First Affiliated Hospital of Nanjing Medical University, ${ }^{\text {b Department }}$ of Pediatrics, Nanjing Maternal and Child Health Hospital of Nanjing Medical University, cMinistry of Education Key Laboratory of Model Animal for Disease Study, Model Animal Research Centre, Nanjing University, Nanjing, P. R. China, dThese authors contributed equally to this work

\section{Key Words}

LnCRNA • pdk1 gene knockout • Heart failure • Microarray

\begin{abstract}
Background/Aims: Previous studies have indicated that long non-coding RNAs (IncRNA) are related to the occurrence and development of many human diseases, such as cancer and the HELLP and the brachydactyly syndromes. However, studies of LncRNA in heart failure have not yet been reported. Here, we investigated cardiac IncRNA expression profiles in the myocardialspecific knockout pdk1 gene (KO) mouse model of heart failure. Methods: Cardiac samples were obtained from PDK1 KO and WT mice on postnatal (P) day 8 (P8) and day 40 (P40), and IncRNA expression profiles were analyzed by sequencing and screening using the Arraystar mouse IncRNA microarray. Quantitative real-time PCR analysis of these IncRNAs confirmed the identity of some genes. Results: Comparisons of the KO and control groups showed fold changes of $>1.5$ in the expression levels of 2,024 IncRNAs at P8, while fold changes of $>2$ in the expression levels of 4,095 IncRNAs were detected at P40. Nineteen IncRNAs were validated by RT-PCR. Bioinformatic and pathway analyses indicated that mkk7, a sense overlap IncRNA, may be involved in the pathological processes of heart failure through the MAPK signaling pathway. Conclusion: These data reveal differentially expressed IncRNA in mice with a myocardial-specific deletion of the $p d k 1$ gene, which may provide new insights into the mechanism of heart failure in PDK1 knockout mice.
\end{abstract}

Copyright $@ 2013$ S. Karger AG, Basel

\section{Introduction}

Although technological advances have led to the improvement of heart failure (HF) treatments, it is still a major cause of morbidity and mortality as well as a significant burden on healthcare systems $[1,2]$. 
HF, being a syndrome, not a disease, is made up of a series of pathological changes in the failing heart, in systems such as energy metabolism, ion channel functions, as well as growth and survival signaling pathways [3-5]. Problems in these complex systems will ultimately lead to fatal heart damage, although the processes by which this occurs remains somewhat elusive.

The 3-phosphoinositide-dependent protein kinase-1(PDK1) was first identified as a serine/threonine kinase. The mouse PDK1 (mPDK1) protein is composed of 559 amino acids and a $\mathrm{COOH}$-terminal pleckstrin homology domain. Murine PDK1 mRNA is broadly expressed in all mouse tissues and in embryonic cells [6]. Previous studies have demonstrated that PDK1, through phosphorylation of the activated AGC protein kinase family and other protein kinases, has a key role in cell growth proliferation, migration and survival, as well as nutrient uptake and storage. These functions of PDK1 have been demonstrated in many types of cancer [7-9].

PDK1 knockout (KO) mice exhibit embryonic fatality at day E9.5 due to multiple abnormalities including lack of somites, forebrain and neural crest-derived tissues. However, PDK1 hypomorphic mice, which exhibit a partial loss of gene function, were $40-50 \%$ smaller than the control animals, and their organ volumes were reduced proportionately $[10,11]$. In the heart tissues specifically, PDK1 KO mice developed and suddenly died of heart failure between 5 and 11 weeks of age. In addition, heart muscle mass was markedly reduced in KO mice due to a reduction in cardiomyocyte volume rather than cardiomyocyte cell number [12-14]. In this study, we investigated the role of long non-coding RNA (lncRNAs) in the $p d k 1$ gene knockout mouse model of heart failure. These mice start expressing the $\alpha$-myosin heavy chain recombinase in cardiomyocytes at postnatal day 7, develop heart failure at postnatal day 40 and die at approximately 5 to 8 weeks of age $[14,15]$. However, both the heart function and histomophology are normal at P8 [14]. Long non-coding RNAs (lncRNAs) have recently emerged as key players in many rapidly growing areas of research, including epigenetics, hormone signaling, development, stem cell biology, cancer, brain function and plant biology [16-26]. LncRNAs are typically 1,000-10,000 residues in length and have little or no ability for protein coding $[27,28]$. An lncRNA can be classified into five major categories, based on their relative positions to neighboring protein coding genes: (1) sense, when overlapping one or more exons of another transcript on the same strand; (2) antisense, when overlapping one or more exons of another transcript on the opposite strand; (3) bidirectional, when the expression of it and a neighboring coding transcript on the opposite strand is initiated in close genomic proximity; (4) intronic, when it is derived wholly from within an intron of a second transcript; and (5) intergenic, when it lies within the genomic interval between two genes [21]. Previous studies have indicated that lncRNAs have a wide range of biological functions mediated via many poorly understood molecular mechanisms, which include cis-tethering or cis-targeting, trans-targeting, allosteric modification and functions as enhancers, decoys, scaffold, and co-activators or co-repressors of gene regulation [28-33]. Existing research on the role of IncRNA in cardiac development and disease has focused on the expression of IncRNA-SRA transcripts in dilated cardiomypothy [34, 35], as well as the regulation and induction of the IncRNA-ALC-1 antisense by ALC-1 in hypertrophic ventricles [36]. Other studies have found IncRNA expression in the myocardium from infants with Tetralogy of Fallot [37]. More recent studies have investigated the role of IncRNA, Braveheart, in cardiovascular lineage commitment [38]. Another tissue-specific lncRNA, Fendrr, has been found to be an essential regulator of heart and body wall development in the mice [39]. However, investigations of the role of IncRNA in cardiac development and pathophysiology are rare, with no current reports on its impact in heart failure.

In this study, we compared the IncRNA expression profiles between $p d k 1$ gene KO mice and matched control mice (intact PDK1) at postnatal day 8 (P8) and day 40 (P40). A small number of mice were evaluated by RT-PCR in a total of six pairs of heart tissue samples from $\mathrm{KO}$ and control mice. Our results suggest that IncRNAs may participate in the progression of $\mathrm{HF}$ and provide key new molecular insights into the mechanisms may underlying HF. 


\section{Materials and Methods}

Experimental animals and tissue collection

The generation of $p d k 1$ gene knockout mice has been previously described [14]. Our experimental animal facility has been accredited by the AAALAC (Association for Assessment and Accreditation of Laboratory Animal Care International) and the IACUC (Institutional Animal Care and Use Committee) of the Model Animal Research Center of Nanjing University approved all animal protocols (AP) used in this study (AP\#: ZY10). Specimens were snap-frozen in liquid nitrogen and subsequently stored at $-80^{\circ} \mathrm{C}$. Total RNA was extracted using TRIzol reagent (Invitrogen, CA, USA) according to the instructions provided by the manufacturer.

\section{Microarray and data analysis}

DNA microarray. The Arraystar mouse IncRNA Array v2.0 was designed for profiling both IncRNAs and protein coding RNAs of the mouse genome. A total of 31,423 lncRNAs were collected from authoritative data sources including RefSeq, UCSC Knowngenes, Ensembl and other related literature. The microarray analysis was performed by KangChen Bio-tech, Shanghai, PR China. For each microarray study, RNA of 3 mouse heart tissue samples from control and KO groups were pooled, and used in hybridization. The array experiment was repeated twice on two different sets of mouse-derived tissues.

RNA labeling and array hybridization. Three samples were hybridized, two biological replicates for each condition (cardiac tissues of control and pdk1 KO mouse, respectively). Sample labeling and array hybridization were performed according to the Agilent One-Color Microarray-Based Gene Expression Analysis protocol (Agilent Technology, CA, USA) with minor modifications. Briefly, mRNA was purified from total RNA after removal of rRNA (mRNA-ONLY ${ }^{\mathrm{TM}}$ Eukaryotic mRNA Isolation Kit, Epicentre). Then, each sample was amplified and transcribed into fluorescent cRNA along the entire length of the transcripts without 3' bias utilizing a random priming method. The labeled cRNAs were purified by RNeasy Mini Kit

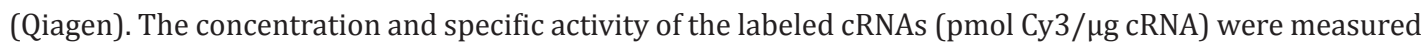
by NanoDrop ND-1000. One $\mu \mathrm{g}$ of each labeled cRNA was fragmented by adding $5 \mu \mathrm{l} 10 \times$ Blocking Agent and $1 \mu \mathrm{l}$ of $25 \times$ Fragmentation Buffer. The mixture was then heated at $60^{\circ} \mathrm{C}$ for $30 \mathrm{~min}$ before the addition of 25 $\mu \mathrm{l} 2 \times$ GE Hybridization buffer to dilute the labeled cRNA. Hybridization solution ( $50 \mu \mathrm{l})$ was dispensed into the gasket slide and assembled with the IncRNA expression microarray slide. The slides were incubated for 17 hours at $65^{\circ} \mathrm{C}$ in an Agilent Hybridization Oven. The hybridized arrays were washed, fixed and scanned using the Agilent DNA Microarray Scanner (part number G2505C). The microarray analysis was performed by KangChen Bio-tech, Shanghai, PR China.

Data analysis. Agilent Feature Extraction software (version 11.0.1.1) was used to analyze the acquired array images. Quantile normalization and subsequent data processing were performed with using the GeneSpring GX v11.5.1 software package (Agilent Technologies). After quantile normalization of the raw data, IncRNAs and mRNAs with at least two out of two samples with flags in Present or Marginal ("All Targets Value") were chosen for further data analysis. Differentially expressed IncRNAs and mRNAs between two samples were identified through fold change filtering. Hierarchical Clustering was performed using the Agilent GeneSpring GX software (version 11.5.1). GO analysis and pathway analysis were performed using in the standard enrichment computation method.

Functional group analysis. Pathway analysis is a functional analysis that maps genes to KEGG (Kyoto Encyclopedia of Genes and Genomes) pathways (http://www.genome.jp/kegg/). The $P$-value (EASEscore, Fisher $P$-value or Hypergeometric $P$-value) denotes the significance of the pathway correlated to the conditions. Lower $P$-values indicate greater significance of the correlation (recommended $P$-value cut-off is 0.05.)

\section{Quantitative real-time PCR}

Total RNA was isolated from P8 and P40 mouse heart tissue using TRIzol (Invitrogen, Carlsbad, CA). The reverse transcription mixture contained $2 \mu \mathrm{g}$ total RNA, $1 \mu \mathrm{l}$ oligo(dT), $1 \mu \mathrm{l} 10 \mathrm{mM}$ dNTP mixture, $4 \mu \mathrm{l}$ $5 \times$ buffer, $2 \mu \mathrm{l} 0.1 \mathrm{M}$ DTT, $1 \mu \mathrm{l}$ M-MLV and an appropriate amount of RNAse-free $\mathrm{H}_{2} \mathrm{O}$ to a total volume of $20 \mu \mathrm{l}$. The reaction was performed at $37^{\circ} \mathrm{C}$ for $2 \mathrm{~min}$ and $37^{\circ} \mathrm{C}$ for $50 \mathrm{~min}$, followed by heat inactivation at $70^{\circ} \mathrm{C}$ for 15 min. Quantitative real-time PCR (qPCR) was performed on an ABI StepOne Plus real-time PCR system (Applied Biosystems, Carlsbad, CA, USA) with $1 \mu \mathrm{l}$ reverse transcription product, $0.25 \mu \mathrm{l}$ forward 
A

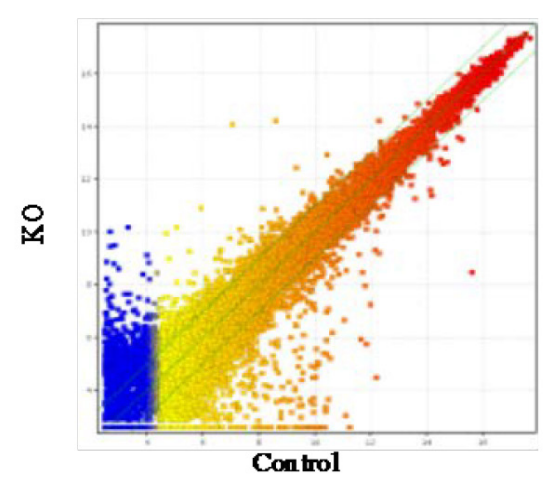

B

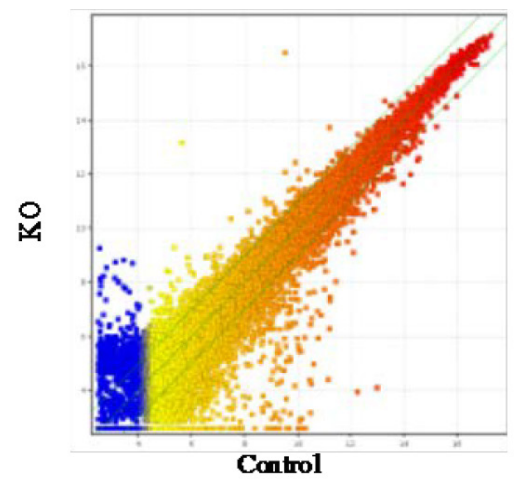

Fig. 1. The expression profiles of IncRNAs and mRNAs were compared between the PDK1 KO group and the paired normal Control group at P40. The scatter plot is a visualization method used for assessing the IncRNA (A) and mRNA (B) expression variations between $\mathrm{KO}$ and Control samples. The values of the $\mathrm{X}$ and $\mathrm{Y}$ axes in the scatter plot are the averaged normalized signal values of the group (log2 scale). The green lines are fold change lines (the default fold change given is 2.0).

Table 1. Relative differential IncRNA and mRNA expression from microarray analysis of P40 cardiac tissue samples

\begin{tabular}{|c|c|c|c|c|c|c|}
\hline Sample & \multicolumn{6}{|c|}{ Long non-coding RNA } \\
\hline ID & & Fold change $>2$ & Fold change $>6-10$ & Fold change $>10$ & Total & Change lncRNA \\
\hline \multirow[t]{2}{*}{ P40 } & Upregulation & 1916 & 116 & 62 & 2094 & 4059 \\
\hline & Downregulation & 1707 & 110 & 148 & 1965 & \\
\hline Sample & Message RNA & & & & & \\
\hline ID & & Fold change $>2$ & Fold change $>6-10$ & Fold change $>10$ & Total & Change lncRNA \\
\hline \multirow[t]{2}{*}{$\mathrm{P} 40$} & Upregulation & 973 & 55 & 30 & 1158 & 3377 \\
\hline & Downregulation & 959 & 140 & 120 & 2219 & \\
\hline
\end{tabular}

and reverse primer (Table 4), and $5 \mu$ l SYBR-Green real-time PCR master mix. The PCR cycling parameters were as follows: $95^{\circ} \mathrm{C}$ for $10 \mathrm{~s}$; 55 cycles of $95^{\circ} \mathrm{C}$ for $5 \mathrm{~s}, 60^{\circ} \mathrm{C}$ for $31 \mathrm{~s}, 72^{\circ} \mathrm{C}$ for $20 \mathrm{~s} ; 78^{\circ} \mathrm{C}$ for $20 \mathrm{~s}$. The level of IncRNA was calculated relative to GAPDH (internal control) using the $2^{-\Delta \Delta c t}$ method. Six mice samples were used for biological replicates and every sample for three technical replicates. The primers are listed in Table 5.

\section{Statistical analysis}

All data were expressed as mean \pm standard deviation. Statistical analysis was performed with the Student's $t$-test for comparison of two groups and analysis of variance (ANOVA) for multiple comparisons. In both cases, differences with $P<0.05$ were considered statistically significant. The statistical significance of microarray results was analyzed in terms of fold change using the Student's $t$-test. False discovery rate (FDR) was calculated to correct the $P$-value. Fold changes $\geq 2$ or $>1.5$, or $\leq 0.25(P<0.01)$ were used as threshold values used to screen differentially expressed IncRNAs and mRNAs.

\section{Results}

LncRNAs are aberrantly expressed in the heart failure group compared with the matched normal group

To study the potential role of lncRNA using the HF mice model, we used microarray analysis to determine the IncRNA and mRNA expression profiles of P40 pdk1gene KO mice with HF (Fig. 1 A, B). Using the sample pool consisting of more than 31,423 lncRNAs, we first assessed the lncRNA expression profile in heart tissue of the HF group and the matched normal mouse group (Table 1). A total of 4,059 lncRNAs were differentially (fold change $>2$, 
A

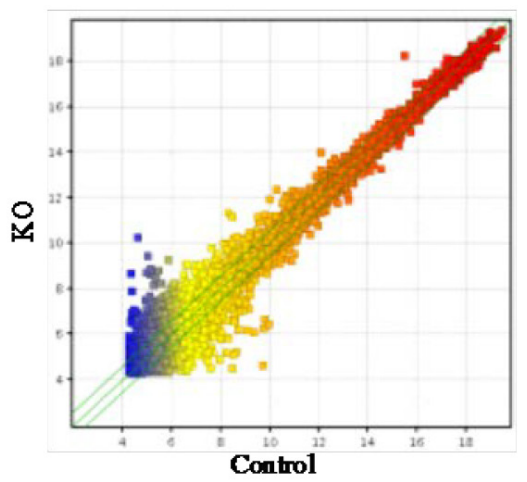

B

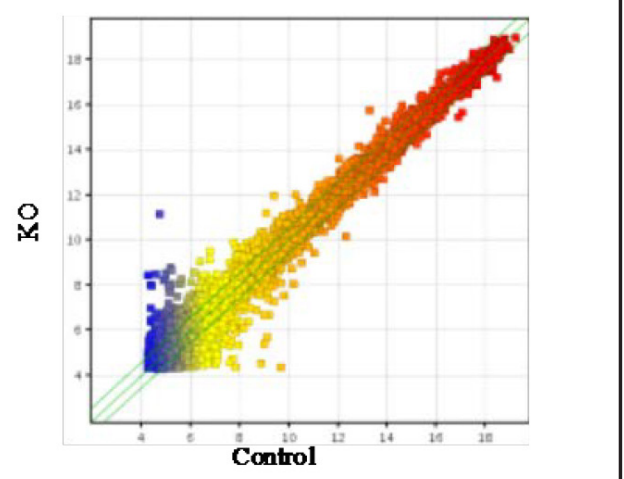

Fig. 2. The expression profiles of lncRNAs and mRNAs were compared between KO and Control groups at P8. The scatter plot is a visualization method used for assessing the lncRNA (A) and mRNA (B) expression variations between $\mathrm{KO}$ and Control samples. The values of the $\mathrm{X}$ and $\mathrm{Y}$ axes in the scatter plot are the averaged normalized signal values of the group (log2 scale). The green lines are fold change lines (the default fold change given is 1.5 ).

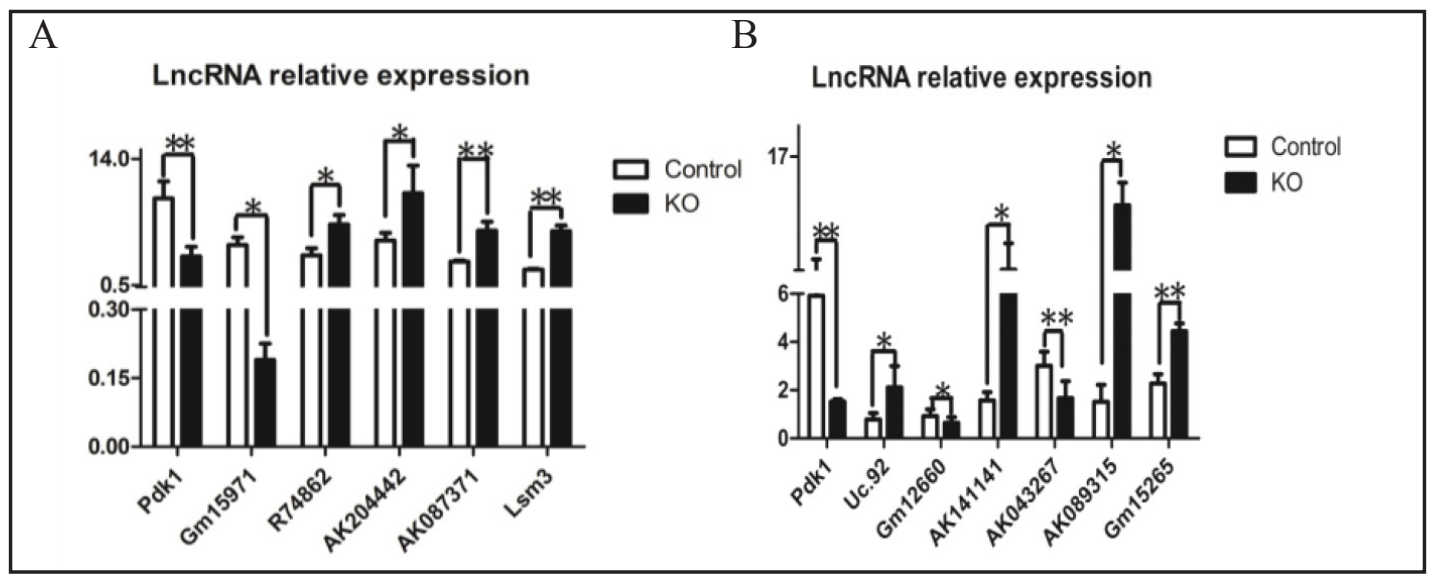

Fig. 3. Differential expression of IncRNAs in cardiac tissue samples obtained at postnatal days 8 and 40 was validated by quantitative real-time PCR; (A) P8 and (B) P40. The quantitative real-time RT-PCR reactions were repeated three times for every lncRNA. The level of IncRNA was calculated relative to GAPDH (internal control) using the $2^{-\Delta \Delta C t}$ method. All reactions were run at least in triplicate. Error bars indicate standard error. ${ }^{*} P<0.05$, ${ }^{* *} P<0.01$.

$P<0.05)$ expressed in the KO group compared to the control group. Among these, 2,094 lncRNAs were upregulated ( $>2$-fold) in experimental group compared to the control group, while 1,965 IncRNA were downregulated.

\section{LncRNAs are also differentially expressed in pdk1gene knockout mouse without heart} failure

To investigate the implications of differential lncRNAs expression in HF mice, we analyzed the IncRNA and mRNA expression profiles in those P8 pdk1 KO mice that did not develop heart failure (Fig. 2A, B). Similar to the data from P40, 2,024 lncRNAs were differentially (fold change $>1.5, P<0.05$ ) expressed between the $p d k 1$ gene knockout and matched normal groups. Among these, 1,224 lncRNA were upregulated ( $>1.5$-fold in experimental group compared to the controls), while 800 lncRNAs were downregulated. 
A

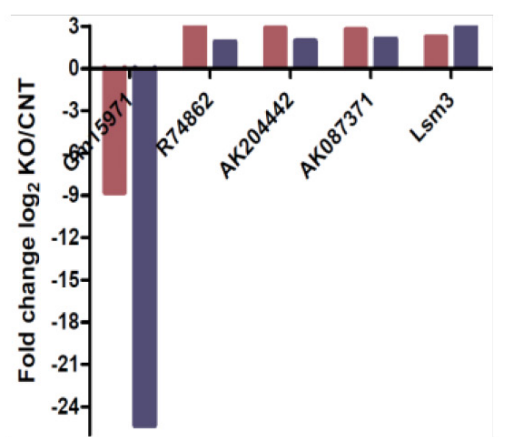

$\mathrm{B}$

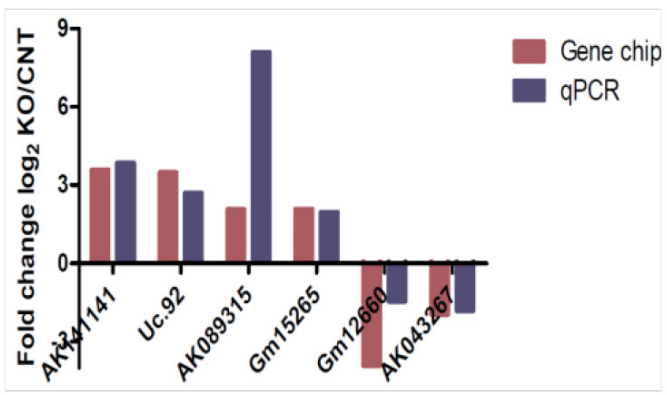

Fig. 4. Comparison of microarray and qPCR data for differentially expressed lncRNAs in cardiac tissue samples obtained at postnatal days 8 and 40; (A) P8 and (B) P40. The heights of the columns in the chart represent the log-transformed median fold changes (KO/Control) in expression. The qPCR results are generally consistent with microarray data.

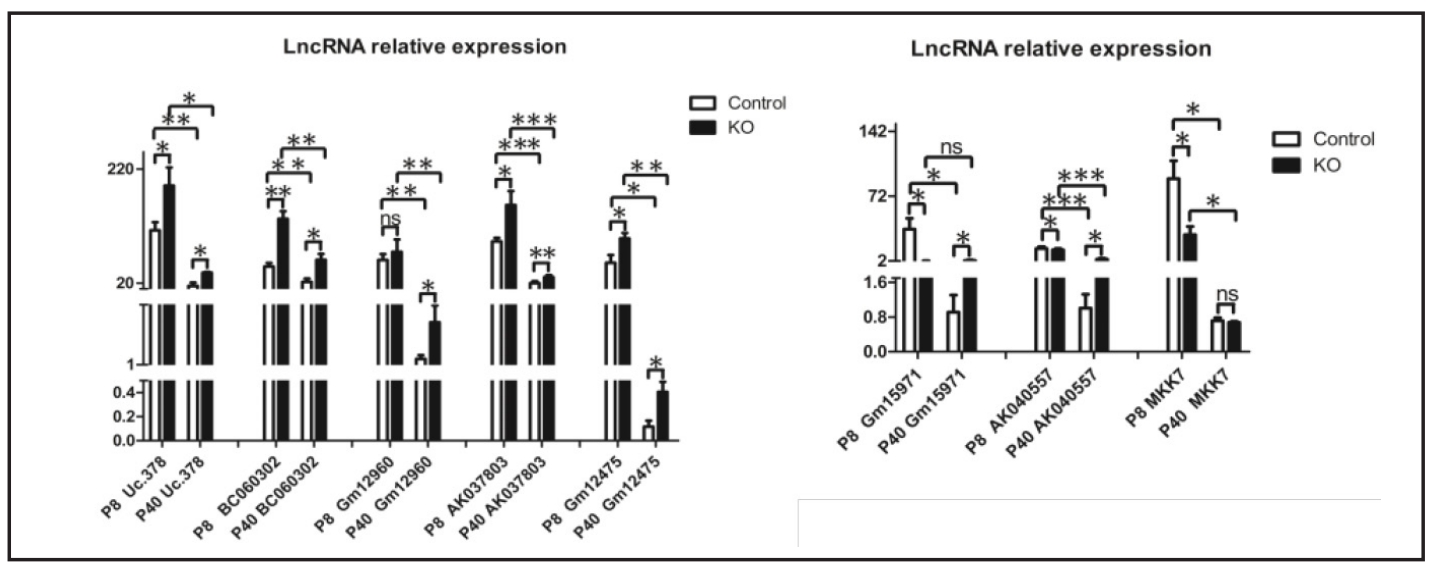

Fig. 5. Comparison of qPCR data for differentially expressed lncRNAs in cardiac tissue samples between $P(8)$ and $P(40)$.The real-time RT-PCR reactions were repeated three times for every lncRNA. The level of IncRNA was calculated relative to GAPDH (internal control) using the $2^{-\Delta \Delta \mathrm{Ct}}$ method. All reactions were run at least in triplicate. Error bars indicate standard error. ${ }^{*} P<0.05{ }^{* *} P<0.01,{ }^{* * *} P<0.001$.

\section{Real-time quantitative PCR validation}

From the P8 differentially expressed IncRNAs, we randomly selected one downregulated lncRNA (Gm15791) and four upregulated lncRNAs (R74862, AK204442, AK087371 and Lsm3). From the P40 differentially expressed lncRNAs, we also randomly selected two downregulated lncRNA (Gm12660 and AK04367) and four upregulated lncRNA (Uc.92, AK141141, AK089315 and Gm15265) for qPCR validation (Fig. 3A, B). The qPCR and microarray data were in accordance (Fig. 4 A, B).

Compared analysis of IncRNAs microarray and validated of several IncRNAs

To identify the specific lncRNAs that participate in the development of heart failure, we analyzed the microarray data of the two experimental time-points (P8 and P40). A total of 93 lncRNAs were consistently upregulated, while 52 were consistently downregulated. Furthermore, 136 IncRNAs were downregulated at P40 after the upregulation at P8 and 51 lncRNAs were downregulated at P8 before upregulation at P40. Moreover, qPCR revealed five consistently upregulated IncRNAs (UC.378, BC060302, Gm12960, AK037803 and Gm12475), as well as three lncRNAs (Gm15791, AK040557 and MKK7) that were downregulated at P8 
Table 2. The RT-PCR results were consistent with the microarray data

\begin{tabular}{llll}
\hline & & \multicolumn{2}{c}{ mean fold change } \\
\hline gene name & regulation & qpcr & chip \\
P8 Gm15971 & down & -19.186 & -8.795761 \\
P8 AK040557 & down & -1.09886 & -0.8860555 \\
P8 MKK7 & down & -2.99873 & -1.6066321 \\
P8 Gm12960 & up & 1.234282 & 1.5142047 \\
P8 AK037803 & up & 1.686044 & 1.5943521 \\
P8 Gm12475 & up & 1.768452 & 3.0566463 \\
P8 Uc.378 & up & 1.685338 & 1.5790685 \\
P8 BC060302 & up & 2.706037 & 1.5210909 \\
& & & \\
P40 Gm15971 & up & 2.759753 & 3.870869 \\
P40 AK040557 & up & 3.825017 & 7.016618 \\
P40 MKK7 & down & -1.05613 & -1.475715 \\
P40 Gm12960 & up & 3.543601 & 4.1962757 \\
P40 AK037803 & up & 1.515246 & 1.817615 \\
P40 Gm12475 & up & 3.485707 & 2.1022792 \\
P40 Uc.378 & up & 2.556295 & 2.35287 \\
P40 BC060302 & up & 2.739006 & 2.02075 \\
\hline
\end{tabular}

before being upregulated in P40 (Fig. 5). The results were consistent with the microarray data (Table 2).

Bioinformatics analysis indicates that MAPK and cell adhesion molecule signaling pathways are involved in the pathology of heart failure pathological process

Pathway analysis of the differentially expressed lncRNAs at P40 in the HF group compared to the controls (which have more associated genes and a lower $P$-value, $<0.05$ ) revealed that 10 different pathways corresponding to the target genes, the top three being MAPK, cell adhesion molecules and the tight junction signaling pathway (Table 3). Pathway analysis of P8 data showed roughly similar results (Table 4).In both cases, the MAPK and cell adhesion molecule signaling pathways showed the most significant changes.

\section{Discussion}

Previous studies have indicated that lncRNAs are involved in many human diseases, such as cancer, HELLP syndrome, brachydactyly syndrome, as well as hypertrophic and dilated cardiomyopathies [25, 34-36, 40, 41]. One study found that ALC-1 antisense mRNA is expressed in human hypertrophic, but not in normal, ventricles. Furthermore, it was shown that higher antisense to sense ALC- 1 mRNA ratios are associated with lower ALC-1 protein expression [36]. Subsequently, the Steroid Receptor RNA Activator (SRA) transcript, which is a long non-coding RNA, functions as a coactivator of nuclear receptor signaling, as well as being an important component of gene insulator complexes found in human dilated cardiomyopathy [34, 35]. Recent studies have also suggested that lncRNAs participate in 
Table 3. Pathways represented among differentially expressed lncRNAs at P40 (microarray data)

\begin{tabular}{|c|c|c|c|}
\hline Term & Count & $P$-value & Genes \\
\hline MAPK signaling pathway & 35 & 0.04749578 & $\begin{array}{l}\text { BDNF,BRAF,CACNA2D1,CACNB1,CACNG3,DUSP4,ELK1,FGF13, } \\
\text { FGF18,GNA12,GNG12,MAP3K2,MAP3K7,MAPK8IP3,MAPT,NFKB } \\
\text { 2,NR4A1,NTRK2,PAK2,PLA2G12A,PLA2G4B,PPM1B,PPP3CA,PPP } \\
\text { 3CB,PPP3R1,PRKCC,PTPN5,PTPRR,RAP1B,RASA1,RASA2,RASGR } \\
\text { F1,RASGRP,RRAS2,TAOK2 }\end{array}$ \\
\hline Tight junction & 31 & 0.000005429382 & $\begin{array}{l}\text { ACTN3,ASH1L,CDK4,CLDN14,CLDN22,CLDN3,CLDN4,CLDN6, } \\
\text { CSDA,CTNNA1,CTTN,EPB4.,EPB4.1L1,EXOC4,F11R,GNAI1,GNAI2, } \\
\text { INADL,MYH1,MYH9,MYL2,PARD3,PPP2R2B,PRKCC,PTEN,RAB3B, } \\
\text { RHOA,RRAS2,SPNB2,TJP1,VAPA }\end{array}$ \\
\hline $\begin{array}{l}\text { Regulation of actin } \\
\text { cytoskeleton }\end{array}$ & 29 & 0.04497438 & $\begin{array}{l}\text { ABI2,ACTN3,APC,ARPC5,BRAF,CFL2,CHRM4,DOCK1,FGF13, } \\
\text { FGF18,GNA12,GNG12,GRLF1,GSN,IQGAP2,ITGA9,ITGB1,MYH9, } \\
\text { MYL2,NCKAP1,PAK2,PFN2,PIK3CB,PIK3CG,PPP1CB,PTK2,RHOA, } \\
\text { RRAS2,WASF1 }\end{array}$ \\
\hline $\begin{array}{l}\text { Cell adhesion molecules } \\
\text { (CAMs) }\end{array}$ & 28 & 0.0005315351 & $\begin{array}{l}\text { CADM3,CD8B1,CLDN14,CLDN22,CLDN3,CLDN4,CLDN6,CNTN1, } \\
\text { F11R,GLG1,H2-AA,H2-D1,H2-EB1,H2-M10.3,H2-M10.6,ITGA9, } \\
\text { ITGB1,MPZL1,NCAM1,NEGR1,NLGN1,NRXN1,NRXN2,PDCD1,PTP } \\
\text { RC,SDC4,SELPLG,VCAN }\end{array}$ \\
\hline $\begin{array}{l}\text { Calcium signaling } \\
\text { pathway }\end{array}$ & 25 & 0.0440985 & $\begin{array}{l}\text { CADM3,CD8B1,CLDN14,CLDN2,CLDN3,CLDN4,CLDN6,CNTN1, } \\
\text { F11R,GLG1,H2-AA,H2-D1,H2-EB1,H2-M10.3,H2-M10.6,ITGA9, } \\
\text { ITGB1,MPZL1,NCAM1,NEGR1,NLGN1,NRXN1,NRXN2,PDCD1, } \\
\text { PTPRC,SDC4,SELPLG,VCAN }\end{array}$ \\
\hline Wnt signaling pathway & 24 & 0.0148108 & $\begin{array}{l}\text { CADM3,CD8B1,CLDN14,CLDN22,CLDN3,CLDN4,CLDN6,CNTN1, } \\
\text { F11R,GLG1,H2-AA,H2-D1,H2-EB1,H2-M10.3,H2-M10.6,ITGA9, } \\
\text { ITGB1,MPZL1,NCAM1,NEGR1,NLGN1,NRXN1,NRXN2,PDCD1, } \\
\text { PTPRC,SDC4,SELPLG,VCAN }\end{array}$ \\
\hline Spliceosome & 23 & 0.005362725 & $\begin{array}{l}\text { ACIN1,CDC40,GM5803,HNRNPA1,HNRNPA3,HNRNPu,PRPF3, } \\
\text { PRPF38B,PRPF4,PRPF40B,RBM17,RBM22,RBMX,RBMXRT, } \\
\text { SF3B1,SMNDC1,SNRNP70,SNW7,SRSF1,SRSF4,SRSF9,THOC4, } \\
\text { WBP11 }\end{array}$ \\
\hline $\begin{array}{l}\text { mRNA surveillance } \\
\text { pathway }\end{array}$ & 20 & 0.001131179 & $\begin{array}{l}\text { ACIN1,CPSF3,CSTF1,DAZAP1,ETF1,FIP1L1,GSPT1,NXT2,PABPC1, } \\
\text { PABPC1L,PABPC4L,PNN,PPP1CB,PPP2R2B,PPP2R5C,RNPS1, } \\
\text { SMG7,THOC4,UPF2,WIBG }\end{array}$ \\
\hline $\begin{array}{l}\text { Toll-like receptor } \\
\text { signaling pathway }\end{array}$ & 10 & 0.04471018 & AKT2,CD14,IFNA4,IL1B,IRAK4,MAPK,PIK3CD,PIK3CG,TLR5,TLR7 \\
\hline $\begin{array}{l}\text { Inositol phosphate } \\
\text { metabolism }\end{array}$ & 7 & 0.04117666 & IMPAD1,INPP5B,IPPK,PIK3C2B,PIK3C2G,PIK3CD,PIK3CG \\
\hline
\end{tabular}

heart development and disease. For example, Fenrr, a tissue-specific lncRNA, is an essential regulator of heart and body wall development in the mouse. Fenrr binds to both PRC2 and TrxG/MLL complexes, and acts as a modulator of chromatin signatures that define gene activity [39]. However, the pathogenesis of HF remains unclear, and there are no reports describing lncRNA expression profiles in the $p d k 1$ gene KO mouse model of heart failure.

In this study, we conducted microarray analysis of the IncRNA expression profile in mice with myocardial-specific $p d k 1$ gene KO at day P8 and P40. Differential lncRNA expression profiles were detected at the two time-points between the PDK1 KO and matched control groups. Of the 4,059 IncRNAs that were differentially expressed in the PDK1 KO group, only 2,024 lncRNAs were differentially expressed in those without HF, indicating that these IncRNAs may be involved in the initiation and progression of HF. Furthermore, comparison analysis of differential lncRNA expression in the PDK1 KO group at P8 and P40 was conducted to determine which lncRNAs are involved in HF development and progression. We randomly selected a small proportion of the total lncRNAs detected in the six $p d k 1$ gene knockout heart samples and their paired tissue samples for validation by qPCR. In total, 19 lncRNAs were evaluated by qPCR to validate the consistency of the test. Finally, bioinformatics analysis was conducted to explore the biological function of the identified lncRNA targets in HF progression. Pathway analysis indicated that the MAPK signaling pathway is involved in heart failure progression. Members of the MAPK family are involved in the regulation of a large variety of cellular processes, such as cell growth, differentiation, development, cell cycle progression, as well as cell death and survival. The major groups of MAPKs found in cardiac tissue include the extracellular signal-regulated kinases (ERKs), the stress-activated/c-Jun 
Table 4. Pathways represented among differentially expressed lncRNAs at P8 (microarray data)

\begin{tabular}{|c|c|c|c|}
\hline Term & Count & $\mathrm{P}$-value & Genes \\
\hline MAPK signaling pathway & 13 & 0.034314 & $\begin{array}{l}\text { CACNG6,CRKL,DUSP16,DUSP8,EGF,FGF23, } \\
\text { GNG12,IKBKG,MYC,NGF,NTF3,PRKACB, } \\
\text { RPS6KA2 }\end{array}$ \\
\hline ErbB signaling pathway & 8 & 0.002668727 & $\begin{array}{l}\text { CACNG6,CRKL,DUSP16,DUSP8,EGF,FGF23, } \\
\text { GNG12,IKBKG,MYC,NGF,NTF3,PRKACB, } \\
\text { RPS6KA2 }\end{array}$ \\
\hline Gap junction & 7 & 0.01065806 & $\begin{array}{l}\text { ADCY9,EGF,GJD2,PRKACB,SRC,TUBB2A, } \\
\text { TUBB2C }\end{array}$ \\
\hline PPAR signaling pathway & 6 & 0.02416941 & $\begin{array}{l}\text { ACADM,ACSL1,CYP4A31,FABP2,HMGCS2, } \\
\text { UCP1 }\end{array}$ \\
\hline Cell adhesion molecules (CAMs) & 20 & 0.000003991549 & $\begin{array}{l}\text { CADM1,CADM3,CDH5,CLDN10,H2-AAH2- } \\
\text { AB1,H2-BL,H2-D1,H2-K1,H2-M3,H2-Q6, } \\
\text { H2-Q7,H2-Q8,H2-T10,H2-T22,H2-T23, } \\
\text { NCAM1,NLGN2,NRXN2,SELE }\end{array}$ \\
\hline Calcium signaling pathway & 18 & 0.0005380389 & $\begin{array}{l}\text { ATP2B1,ATP2B3,BST1,CACNA1E,CAMK2B, } \\
\text { CAMK4,CD38,DRD5,EDNRB,ITPKB,ITPR1, } \\
\text { NOS2,P2RX7,PDE1C,PPP3CA,PRKCB,PTAFR, } \\
\text { SPHK1 }\end{array}$ \\
\hline Regulation of actin cytoskeleton & 15 & 0.03746045 & $\begin{array}{l}\text { BAIAP2,CHRM4,FGD3,FGF20,FGF3,IQGAP2, } \\
\text { ITGA10,ITGB6,MAPK1,MAPK3,NCKAP1L, } \\
\text { PAK6,PFN3,TIAM2,WASF1 }\end{array}$ \\
\hline Toll-like receptor signaling pathway & 14 & 0.00008043762 & $\begin{array}{l}\text { CCL3,CCL4,CCL5,CXCL10,CXCL9,IFNA13, } \\
\text { IL12B,IRF3,IRF7,MAPK1,MAPK3,TAB1, } \\
\text { TIRAP,TLR5 }\end{array}$ \\
\hline $\begin{array}{l}\text { Endocrine and other factor- } \\
\text { Regulative calcium reabsorption }\end{array}$ & 6 & 0.03007296 & AP2S1,ATP2B1,CALB1,CLTC,DNM1,PRKCB \\
\hline
\end{tabular}

Table 5. LncRNA primers for quantitative real-time PCR analysis

\begin{tabular}{lll}
\hline Gene name & Forward $\left(5^{\prime}-3^{\prime}\right)$ & Reverse $\left(5^{\prime}-3^{\prime}\right)$ \\
\hline PDK1 & AAAACAAAGTCCGTATG & TCGTCGTCCTGAAATGTA \\
GAPDH & GGCACAGTCAAGGCTGAGAATG & ATGGTGGTGAAGACGCCAGTA \\
Gm15971 & ATACTACCCACCTGACTTTG & CATCAGCCATACCACATAC \\
R74862 & TCTGTCTCCAAAGAACCCTA & AACACCATCAAGCCCACT \\
AK204442 & AACACCATCAAGCCCACT & TAGTTCTTTCCCTTGTGG \\
AK087371 & CTCCGCTTGCCTCCTT & CTTCTGCTCCCGTGGT \\
Lsm3 & CGGCCTAAGGTTTCTGAGTT & GGTATTGGTGGTCTGTTGCT \\
Uc.92 & CTTGGTGCGGAGGTTATG & TGATGGACACGGCAGAAG \\
Gm12660 & GGACAAGTGGGTCTAGGTTCA & GGTTGGTCTGGCATCTTTG \\
AK141141 & GACGCAGCTAGATTTCGG & CCATTGCCTGGTTGTTTG \\
AK043267 & CCTGCCTTCTGTTTGGAC & ATTGGTAGCCTTGCTCTG \\
AK089315 & AGGGTTGTGGTTGTAGGG & CTGCGATGATGACGATGA \\
Gm15265 & GGGGTGAGCTGGAAAGGA & CAGGCACAACGGGAACAT \\
Uc.378 & AGACCACCAAAGATTCCC & CCTGAGCCATACCCAGAT \\
BC060302 & GCCTCCATTGCAGGAACA & GCTTCACTGGGTCTGGTTGT \\
Gm12960 & GGCAGCAGAGGTAGTTAT & TATCCACCACCCTTCCAT \\
AK037803 & GCGAGCCTTCCAGACAAA & TCTTCGGAGCGATTCAGC \\
Gm12475 & TCGCCATCTCCAGTTCCT & CAGCCTTCTTCATCCACAAA \\
AK040557 & CTGCGATGGTACGAGGAC & CAATCAGTGGCTGCGAAA \\
MKK7 & GGCACCTTCATCACCAAC & CAATCGCCACAGTCATCTT \\
\hline
\end{tabular}

NH2-terminal kinases (SAPK/JNKs), p38-MAPK, and ERK5/big MAPK 1 (BMK1). Activation of the MAPK families in the heart plays a key role in the pathogenesis of various processes, such as myocardial hypertrophy and its transition to heart failure, ischemic and reperfusion injury, as well as cardio-protection conferred by ischemia- or pharmacologically-induced preconditioning [42]. Some previous studies have elucidated the biological role of MAPK signaling cascades during the development of hypertrophy and its transition to heart failure 
[43-45]. In our study, biological analysis suggested that the sequence of $m k k 7$, a sense overlap lncRNA, stretches from 4238828 to 4251420 on the chromosome 8 sense strand. Furthermore, $\operatorname{map} 2 \mathrm{k} 7, a$ gene in the proximity of mkk7, is also on the chromosome 8 sense strand start, and stretches from 4238739 to 4247897, while dual-specific mitogenactivated protein kinase kinase 7 (MKK7), encoded by the map2k7 gene, is a member of the MAPK family and activates JNK isoforms [46]. Using transgenic mouse models with cardiacspecific and temporally regulated expression of activated mutants MKK7, Scherise and Ota demonstrated that MKK7, along with other specific pathways, contribute specifically to different aspects of HF pathology. [47]. Similarly, Wang et al. showed that expression of both wild-type and constitutive mutants of MKK7, as well as specific activation of the JNK pathway, led to the induction of the hypertrophic responses in the heart [48]. Here, we found that $m k k 7$ was downregulated $(\mathrm{p}<0.05)$ in cardiomyocytes at P8 in the PDK1 KO group compared to the control group; however, this effect did not reach the level of statistical significance at P40. Furthermore, IncRNAs have been shown to regulate target gene expression by a trans-mechanism [30, 31]. Therefore, our data indicate that $m k k 7$, a sense overlap lncRNA, may play an important role in the development and progression of heart failure through the MAPK signaling pathway.

We determined that lncRNAs were abnormally expressed in $p d k 1$ gene knockout mice and identified several lncRNAs that potentially participate in the initiation and progression of heart failure. Furthermore, we showed that the regulatory roles of these lncRNAs in the pathogenesis of heart failure may be associated with the MAPK signaling pathways. However, further investigations are required to clarify the exact signaling pathways that utilize lncRNAs to regulate the development of heart failure, and to elucidate the molecular mechanisms and biological functions of lncRNAs in heart failure pathology.

\section{Conflict of Interest}

The authors declare no conflict of interest.

\section{Acknowledgements}

This study was supported by grants from the National Natural Science Foundation of China (No. 81070138), the National Natural Science Foundation of Jiangsu Province of China (BK.2010582), the Talent Foundation of Jiangsu Province of China (WSN-020) and the Priority Academic Program Development of Jiangsu Higher Education Institutions (PAPD). We thank Zhouzhou Yang of the Model Animal Research Centre, Nanjing University for providing the pdk1 knockout mouse.

\section{References}

1 Juenger J, Schellberg D, Kraemer S, Haunstetter A, Zugck C, HerzogW, Haass M: Health related quality of life in patients with congestive heart failure: comparison with other chronic diseases and relation to functional variables. Heart 2002;87235-241.

2 Hobbs FD, Kenkre JE, Roalfe AK, Davis RC, Hare R, Davies MK: Impact of heart failure and left ventricular systolic dysfunction on quality of life: a cross-sectional study comparing common chronic cardiac and medical disorders and a representative adult population. Eur Heart J 2002;23:1867-1876.

3 Roger VL: The changing landscape of heart failure hospitalizations. J Am Coll Cardiol 2013;61:1268126870.

4 Neubauer S: The failing heart - an engine out of fuel. N Engl J Med 2007;356:1140-1151.

5 Jankowska EA, von Haehling S, Anker SD, Macdougall IC, Ponikowski P: Iron deficiency and heart failure: diagnostic dilemmas and therapeutic perspectives. Eur Heart J 2013;34:816-829. 
6 Dong LQ, Zhang RB, Langlais P, He H, Clark M, Zhu L, Liu F: Primary Structure, Tissue Distribution, and Expression of Mouse Phosphoinositide-dependent Protein Kinase-1, a Protein Kinase That Phosphorylates and Activates Protein Kinase Czeta. J Biol Chem 1999;274:8117-8122.

7 Belgardt BF, Husch A, Rother E, Ernst MB, Wunderlich FT, Hampel B, Klöckener T, Alessi D, Kloppenburg P, Brüning JC: PDK1 deficiency in POMC-expressing cells reveals FOXO1-dependent and -independent pathways in control of energy homeostasis and stress response. Cell Metab 2008;7:291-301.

8 Yin Y, Yuan H, Wang C, Pattabiraman N, Rao M, Pestell RG, Glazer RI: 3-phosphoinositide-dependent protein kinase-1 activates the peroxisome proliferator-activated receptor-gamma and promotes adipocyte differentiation.Mol Endocrinol 2006;20:268-278.

9 Li Y, Yang KJ, Park J: Multiple implications of 3-phosphoinositide-dependent protein kinase 1 in human cancer. World J Biol Chem 2010;1:239-247.

10 Lawlor MA, Mora A, Ashby PR, Williams MR, Murray-Tait V, Malone L, Prescott AR, Lucocq JM, Alessi DR: Essential role of PDK1 in regulating cell size and development in mice. EMBO J 2002;21:3728-3738.

-11 Bayascas JR, Wullschleger S, Sakamoto K, García-Martínez JM, Clacher C, Komander D, van Aalten DM, Boini KM, Lang F, Lipina C, Logie L, Sutherland C, Chudek JA, van Diepen JA, Voshol PJ, Lucocq JM, Alessi DR: Mutation of the PDK1 PH domain inhibits protein kinase B/Akt, leading to small size and insulin resistance. Mol Cell Biol 2008;28:3258-3272.

12 Mora A, Davies AM, Bertrand L, Sharif I, Budas GR, Jovanović S, Mouton V, Kahn CR, Lucocq JM, Gray GA, Jovanović A, Alessi DR: Deficiency of PDK1 in cardiac muscle results in heart failure and increased sensitivity to hypoxia. EMBO J 2003;22:4666-4676.

13 Ito K, Akazawa H, Tamagawa M, Furukawa K, Ogawa W, Yasuda N, Kudo Y, Liao CH, Yamamoto R, Sato T, Molkentin JD, Kasuga M, Noda T, Nakaya H, Komuro I: PDK1 coordinates survival pathways and betaadrenergic response in the heart. Proc Natl Acad Sci USA 2009;106:8689-8694.

14 Di RM, Feng QT, Chang Z, Luan Q, Zhang YY, Huang J, Li XL, Yang ZZ: PDK1 plays a critical role in regulating cardiac function in mice and human. Chin Med J 2010;123:2358-2363.

-15 Ng WA, Grupp IL, Subramaniam A, Robbins J: Cardiac myosin heavy chain mRNA expression and myocardial function in the mouse heart. Circ Res 1991;68:1742-1750.

16 Pauli A, Rinn JL, Schier AF: Non-coding RNAs as regulators of embryogenesis. Nat Rev Genet 2011;12:136149.

17 Wang X, Song X, Glass CK, Rosenfeld MG: The long arm of long noncoding RNAs: roles as sensors regulating gene transcriptional programs. Cold Spring Harb Perspect Biol 2011;3:a003756.

18 Gupta RA, Shah N, Wang KC, Kim J, Horlings HM, Wong DJ, Tsai MC, Hung T, Argani P, Rinn JL, Wang Y, Brzoska P, Kong B, Li R, West RB, van de Vijver MJ, Sukumar S, Chang HY: Long non-coding RNA HOTAIR reprograms chromatin state to promote cancer metastasis. Nature 2010;464:1071-1076.

19 Barsotti AM, Prives C: Noncoding RNAs: the missing "linc" in p53-mediated repression. Cell 2010;142:358360.

20 Valadkhan S, Nilsen TW: Reprogramming of the non-coding transcriptome during brain development. J Biol 2010;9:5.

21 Ponting CP, Oliver PL, Reik W: Evolution and functions of long noncoding RNAs. Cell 2009;136:629-641.

-22 Gong C, Maquat LE: IncRNAs transactivateSTAU1-mediated mRNA decay by duplexing with3‘ UTRs via Alu elements. Nature 2011;470:284-288.

23 Ietswaart R, Wu Z, Dean C: Flowering time control: another window to the connection between antisenseRNA and chromatin. Trends Genet 2012;28:445-453.

24 Swiezewski S, Liu F, Magusin A, Dean C: Coldinduced silencing by long antisense transcripts of an Arabidopsis Polycomb target. Nature 2009;462:799-802.

25 Gutschner T, Diederichs S: The hallmarks of cancer: a long non-coding RNA point of view. RNA Biol 2012;9:703-719.

26 Dinger ME, Arefin AS, Berretta R, Moscato P: The hippocampal expression of 31 noncoding Rnas is upregulated in Alzheimer's disease patients and three positively correlate with MMSE results and other biomarkers of disease progression. Alzheimers Dement 2010;e47-e48.

27 Chen LL, Carmichael GG: Decoding the function of nuclear long non-coding RNAs. Curr Opin Cell Biol 2010;22:357-364. 
28 Ravasi T, Suzuki H, Pang KC, Katayama S, Furuno M, Okunishi R, Fukuda S, Ru K, Frith MC, Gongora MM, Grimmond SM, Hume DA, Hayashizaki Y, Mattick JS: Experimental validation of the regulated expression of large numbers of non-coding RNAs from the mouse genome. Genome Res 2006;16:11-19.

-29 Cesana M, Cacchiarelli D, Legnini I, Santini T, Sthandier O, Chinappi M, Tramontano A, Bozzoni I: A long noncoding RNA controls muscle differentiation by functioning as a competing endogenous RNA. Cell 2011;147:358-369.

-30 Hung T, Chang HY: Long noncoding RNA in genome regulation: prospects and mechanisms. RNA Biol 2010;7:582-585.

- 31 Wang KC, Chang HY: Molecular mechanisms of long noncoding RNAs. Mol Cell 2011;43:904-914.

-32 Mondal T, Kanduri C: Noncoding RNA scaffolds in pluripotency. Circ Res 2012;110:1162-1165.

33 Moran VA, Perera RJ, Khalil AM: Emerging functional and mechanistic paradigms of mammalian long noncoding RNAs. Nucleic Acids Res 2012;40:6391-6400.

-34 Cooper C, Vincett D, Yan Y, Hamedani MK, Myal Y, Leygue E: Steroid Receptor RNA Activator bi-faceted genetic system: heads or tails? Biochimie 2011;93:1973-1980.

-35 Friedrichs F, Zugck C, Rauch GJ, Ivandic B, Weichenhan D, Müller-Bardorff M, Meder B, El Mokhtari NE, Regitz-Zagrosek V, Hetzer R, Schäfer A, Schreiber S, Chen J, Neuhaus I, Ji R, Siemers NO, Frey N, Rottbauer W, Katus HA, Stoll M: Three cosegregating genes as determinants of cardiomyopathy. Genome Res 2009;19:395-403.

-36 Ritter O, Haase H, Schulte HD, Lange PE, Morano I: Remodeling of the hypertrophied human myocardium by cardiac bHLH transcription factors. J Cell Biochem 1999;74:551-561.

- 37 O‘Brien JE Jr, Kibiryeva N, Zhou XG, Marshall JA, Lofland GK, Artman M, Chen J, Bittel DC: Noncoding RNA expression in myocardium from infants with tetralogy of Fallot. Circ Cardiovasc Genet 2012;5:279-286.

-38 Klattenhoff CA, Scheuermann JC, Surface LE, Bradley RK, Fields PA, Steinhauser ML, Ding H, Butty VL, Torrey L, Haas S, Abo R, Tabebordbar M, Lee RT, Burge CB, Boyer LA: Braveheart, a long noncoding RNA required for cardiovascular lineage commitment. Cell 2013;152:570-583.

-39 Grote P, Wittler L, Hendrix D, Koch F, Währisch S, Beisaw A, Macura K, Bläss G, Kellis M, Werber M, Herrmann BG: The tissue-specific lncRNA Fendrr is an essential regulator of heart and body wall development in the mouse. Dev Cell 2013;24:206-214.

-40 Maass PG, Rump A, Schulz H, Stricker S, Schulze L, Platzer K, Aydin A, Tinschert S, Goldring MB, Luft FC, Bähring S: A misplaced lncRNA causes brachydactyly in humans. J Clin Invest 2012;122:3990-4002.

-41 van Dijk M, Thulluru HK, Mulders J, Michel OJ, Poutsma A, Windhorst S, Kleiverda G, Sie D, Lachmeijer AM, Oudejans CB: HELLP babies link a novel lincRNA to the trophoblast cell cycle. J Clin Invest 2012;122:40034011.

42 Ravingerová T, Barancík M, Strnisková M: Mitogen-activated protein kinases: A new therapeutic target in cardiac pathology. Mol Cell Biochem 2003;247:127-138.

43 Flesch M, Margulies KB, Mochmann HC, Engel D, Sivasubramanian N, Mann DL: Differential regulation of mitogen-activated protein kinases in the failing human heart in response to mechanical unloading. Circulation 2001;104:2273-2276.

44 Cook SA, Sugden PH, Clerk A: Activation of c-Jun N-terminal kinases and p38-mitogen-activated protein kinases in human heart failure secondary to ischaemic heart disease. J Mol Cell Cardiol 1999;31:14291434.

-45 Haq S, Choukroun G, Lim H, Tymitz KM, del Monte F, Gwathmey J, Grazette L, Michael A, Hajjar R, Force T, Molkentin JD: Differential activation of signal transduction pathways in human hearts with hypertrophy vs. advanced heart failure. Circulation 2001;103:670-677.

-46 Foltz IN, Gerl RE, Wieler JS, Luckach M, Salmon RA, Schrader JW: Human mitogen-activated protein kinase kinase 7 (MKK7) is a highly conserved c-Jun N-terminal kinase/stress-activated protein kinase (SAPK/JNK) activated by environmental stresses and physiological stimuli. J Biol Chem 1998;273:9344-9351.

47 Mitchell S, Ota A, Foster W, Zhang B, Fang Z, Patel S, Nelson SF, Horvath S, Wang Y: Distinct gene expression profiles in adult mouse heart following targeted MAP kinase activation. Physiol Genomics 2006;25:50-59.

48 Wang Y, Su B, Sah VP, Brown JH, Han J, Chien KR: Cardiac hypertrophy induced by mitogen-activated protein kinase kinase 7, a specific activator for c-Jun NH2-terminal kinase in ventricular muscle cells. J Biol Chem 1998;273:5423-54236. 